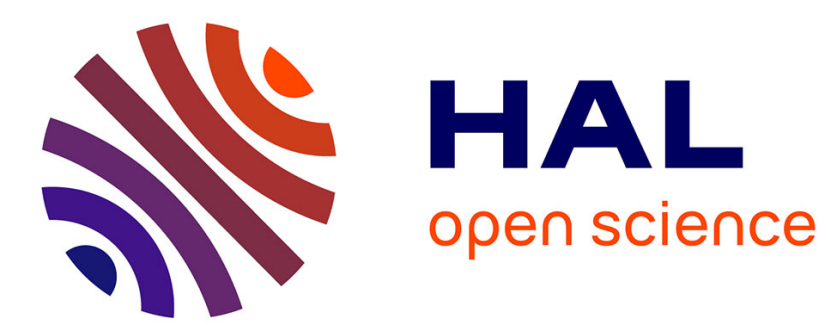

\title{
Parents' appraisals, reflected appraisals, and children's self-appraisals of sport competence: A yearlong study
} Julien Bois, Philippe Sarrazin, Robert Brustad, Julien Chanal, David Trouilloud

\section{- To cite this version:}

Julien Bois, Philippe Sarrazin, Robert Brustad, Julien Chanal, David Trouilloud. Parents' appraisals, reflected appraisals, and children's self-appraisals of sport competence: A yearlong study. Journal of Applied Sport Psychology, 2005, 17, pp.273-289. 10.1080/10413200500313552 . hal-00389002

\section{HAL Id: hal-00389002 https://hal.science/hal-00389002}

Submitted on 27 May 2009

HAL is a multi-disciplinary open access archive for the deposit and dissemination of scientific research documents, whether they are published or not. The documents may come from teaching and research institutions in France or abroad, or from public or private research centers.
L'archive ouverte pluridisciplinaire HAL, est destinée au dépôt et à la diffusion de documents scientifiques de niveau recherche, publiés ou non, émanant des établissements d'enseignement et de recherche français ou étrangers, des laboratoires publics ou privés. 
2
Running head: REFLECTED APPRAISAL PROCESS

Parents' appraisals, reflected appraisals, and children's self-appraisals of sport competence: A yearlong study.

\section{Journal of Applied Sport Psychology, 17, 273-289.}

\author{
Julien E. Bois, Philippe G. Sarrazin
}

University J. Fourier of Grenoble, France

Robert J. Brustad

University of Northern Colorado, United States

Julien P. Chanal and David O. Trouilloud

University J. Fourier of Grenoble, France

Submission date: August 20, 2003

Revised October 9, 2004

Accepted for publication January 9, 2005 
2 This study investigated the contribution of the reflected appraisal process to the ontogeny

3 of children's self-perceptions of physical competence. Emanating from symbolic

4 interactionist thought, reflected appraisals refer to individuals' perceptions of others'

5 evaluations of their abilities. The influence of parents' appraisals of their child's

6 competence on the child's self-appraisals was hypothesized to be mediated by parents'

7 reflected appraisals. Data were collected from a sample of 147 sixth graders and their

8 parents in three waves over one school year. Structural equation modeling revealed that (1)

9 parents' appraisals at Wave 1 influenced children's reflected appraisals of parents at Wave

$10 \quad 2$; (2) reflected appraisals at Wave 2 influenced children's self-appraisals at Wave 3,

11 controlling for both the child's actual level in sport (as assessed by the child's grade in

12 physical education) and the child's self-appraisals at Wave 1; and (3) the influence of

13 parents' appraisals on their child's self-appraisals was nonsignificant when reflected

14 appraisals were controlled for. This study supported the mediational role of the reflected

15 appraisal process. The findings from this study provide a unique contribution to the sport

16 socialization knowledge base by highlighting the role of the reflected appraisal process in

17 the formation of children's self-appraisals of ability.

19 Key words: reflected appraisal, parental influence, perceived competence, physical

20 activity, mediation, motivation. 
Parents' appraisals, reflected appraisals, and children's self-appraisals of sport competence: A yearlong study.

Numerous theoretical models in contemporary psychology have highlighted the role of perceived competence, or ability, as a central antecedent of achievement motivation and behavior (e.g., Deci \& Ryan, 2000; Eccles, Wigfield \& Schiefele, 1998; Elliot \& Church, 1997; Harter, 1981). Although these frameworks differ from each other in numerous ways, each proposes that individuals who have high perceptions of their ability in a particular achievement domain will demonstrate greater motivation, as demonstrated through their decision to become involved, as well as by their levels of effort, perseverance, and affective characteristics in a given context. In the sport and physical activity setting, considerable support has been found for the role of perceived competence in contributing to motivation (for reviews, see Weiss \& Ebbeck, 1996; Weiss \& FerrerCaja, 2002).

Given the influence of competence perceptions on motivation, an important area of study involves understanding the processes individuals use to evaluate or judge their personal competence or ability in achievement contexts. Although much of this research has been conducted in academic contexts (e.g., Stipek \& Mac Iver, 1989), a handful of studies have also examined these issues in the physical activity domain (see for reviews, Horn \& Amorose, 1998; Horn \& Harris, 1996; Weiss, Ebbeck \& Horn, 1997). Several theoretical frameworks have highlighted the importance of significant others in shaping one's self-perceptions. Contemporary developmental and social psychologists (e.g., Harter, 1998; Eccles et al., 1998) have continued in the line of symbolic interactionists such as Cooley (1902) and Mead (1934) in asserting that our self-perceptions develop and change in relation to other people in the social environment. Specifically, our self-perceptions tend to reflect the appraisals of others. This process, whereby perceptions of others' evaluations 
1 function as a mirror in which one sees oneself, has been referred to as the reflected

2 appraisal process (see Felson, 1993; Kinch, 1963; Shrauger \& Schoeneman, 1979; Tice \&

3 Wallace, 2003). In essence, the reflected appraisal process consists of three elements (Felson, 1993;

5 Kinch, 1963; Shrauger \& Schoeneman, 1979), including the individual's self-appraisals or

6 self-perceptions, the actual appraisals of significant others, and the person's perceptions of

7 those appraisals, called reflected appraisals. Moreover, theory suggests three basic

8 postulates (Felson, 1993). The first postulate asserts that people are generally accurate to

9 some extent in perceiving what others think of them (Cooley, 1902; Mead, 1934). In sport,

10 for example, a child may believe that his/her father perceives him/her as having high,

11 moderate, or low ability through the use of varied indices such as the father's enthusiasm

12 level, the amount of attention provided, the feedback and encouragement that the father

13 displays, and the participatory opportunities that he offers to the child. The second

14 postulate is that reflected appraisals are generally internalized by the child, whether they

15 are positive or negative, accurate or not. In this regard, if the child believes that his or her

16 parent has a positive appraisal of his or her sport competence he or she is likely to develop

17 a similarly positive perception of sport competence. In contrast, if the child believes that

18 the parent has a less favorable view of their competence, he or she is likely to perceive

19 himself or herself as less competent in sport. In the ontogeny of self-appraisals, the

20 symbolic interactionist perspective gives critical importance to the internalization of the

21 reflected appraisal. The third postulate is that the actual appraisals of others influence self-

22 appraisals indirectly, as mediated by reflected appraisals. That is, actual appraisals of

23 others have no effect on self-appraisals when reflected appraisals have been taken into 24 account. 
Few researchers have investigated the issue raised by the first postulate (see for

2 reviews, Felson, 1993; Shrauger \& Schoeneman, 1979). Generally, the studies that have

3 been conducted have found weak correlations between reflected appraisals and the actual

4 appraisals of others. In other words, respondents are not very accurate in guessing what

$5 \quad$ significant others think of them, probably because others often conceal their actual

6 opinions, particularly when these opinions are negative (Felson, 1989, 1993; Tice \&

7 Wallace, 2003). That is why Shrauger and Schoeneman (1979) have changed the original

8 metaphor somewhat by suggesting that people see "through the looking glass darkly."

9 Nevertheless, studies (e.g., Malloy, Albright, Kenny, Agatstein, \& Winquist, 1997) have

10 found that the degree of accuracy depends on the significant other with whom one is

11 interacting. In this research, people were most accurately aware of the perceptions of

12 family members rather than other people such as friends or coworkers.

13 Many investigations have provided support for the second postulate, namely the

14 relationship between individuals' self-appraisals and the reflected appraisals of various

15 significant others (see for reviews, Harter, 1998; Schrauger \& Schoeneman, 1979). In the

16 sport and physical activity domain, some studies have revealed a correspondence between

17 the reflected appraisals of parents and the physical self-appraisals of children and

18 adolescents (e.g., Babkes \& Weiss, 1999; Brustad, 1993, 1996; Kimiecik, Horn, \& Shurin,

19 1996). Two recent studies by Amorose $(2002,2003)$ found that athletes' self-appraisals of

20 competence could be predicted by the reflected appraisals of mothers, fathers, coaches, and

21 teammates.

22 Very few studies have attempted to test the third postulate of the theory, namely

23 that reflected appraisals mediate the influence of another person's actual appraisal on the

24 individual's self-appraisal. Support for the two first postulates is, by itself, not sufficient to

25 prove the mediation effect of the reflected appraisal process (Shrauger \& Schoeneman, 
1 1979). It is also necessary to demonstrate the existence of a relationship between the actual

2 appraisals of others and individuals' own self-appraisals as well as a diminishment or a

3 disappearance of the strength of this relationship when reflected appraisals are controlled

4 for (see Baron \& Kenny, 1986).

A number of studies have examined the relationship between the actual appraisals

6 of others and individuals' self-appraisals (see for a review, Eccles et al., 1998; Shrauger \&

7 Schoeneman, 1979). The majority of these studies have found significant relationships

8 between the two, although the magnitude of the relationship tends to be moderate. Studies

9 have found that children's self-appraisals are linked to their parents' appraisals of the

10 child's capacity in both academic (e.g., Frome \& Eccles, 1998; Parsons et al., 1982;

11 Phillips, 1987) and sport (e.g., Bois, Sarrazin, Brustad, Trouilloud, \& Cury, in press, 2002;

12 Dempsey, Kimiecik, \& Horn, 1993; Felson \& Reed, 1986; Jacobs \& Eccles, 1992)

13 domains. For example, using structural equation modeling on a sample of third through

14 fifth grade children, Bois et al. (2002) demonstrated that mothers' appraisals of her child's

15 sport competence predicted the child's self-appraisal of sport competence one year later

16 controlling for both the child's initial self-appraisal and their actual physical performance.

17 Nevertheless, none of these studies mentioned has directly tested whether such influences occur through a process of internalization of reflected appraisals.

Few studies have specifically tested if actual appraisals have an effect on selfappraisals when reflected appraisals are controlled for. Three studies carried out with

21 adults have supported the mediating role of the reflected appraisal on several self-attributes

22 (Ichiyama, 1993; Jussim, Soffin, Brown, Ley, \& Kohlhepp, 1992; Swann, Milton, \&

23 Polzer, 2000). Only one study to our knowledge has been conducted with children

24 (Felson, 1989) and this study did not support the mediation hypothesis. More precisely,

25 using a sample of fourth through seventh grade children and longitudinal data, Felson 
1 investigated the role of reflected appraisals in mediating the influence of parents'

2 appraisals on children's self-appraisals in relation to children's self-evaluations in the

3 academic and athletic domains as well as to their self-evaluations of appearance and

4 popularity over a one-year period. Findings revealed that the reflected appraisals of

5 mothers and fathers were very similar, and could be combined into a single variable

6 representing the reflected appraisals of "parents." The main findings were consistent

7 across the four domains and indicated that parents' actual appraisals affected both reflected

8 appraisals and children's self-appraisals and that reflected appraisals had substantial effects

9 on self-appraisals, after controlling for the self-perceptions of children one year earlier.

10 However, the magnitude of the effect of parents' appraisals on children's self-appraisals

11 was not significantly reduced after controlling for the reflected appraisals. This finding,

12 which casts doubt on a basic component of the reflected appraisal process, deserves further

13 examination.

14 The present study

15 The purpose of this study was to examine the reflected appraisal process as it

16 applies to the influence of parents on sixth graders' self-appraisals of sport competence.

17 For a number of reasons it is generally assumed that parents have a substantial influence on

18 their children's self-appraisals in school (e.g., Eccles et al., 1998; Jacobs \& Eccles, 1992)

19 and sport (e.g., Brustad et al., 2001; Greendorfer, 1992). First, parents are typically

20 responsible for providing children with their initial opportunities to play sport and parents

21 are integrally involved in the youth sport experience (Brustad et al, 2001; Greendorfer,

22 1992). Second, parental feedback is highly salient to youngsters during childhood and the

23 early adolescent years. Research indicates that youngsters are likely to use adult sources of

24 feedback in assessing their competence in various achievement domains throughout

25 childhood and into early adolescence (Frieze \& Bar-Tal, 1980; Horn \& Weiss, 1991). As 
1 children enter adolescence, they also tend to become increasingly reliant on peer sources of

2 feedback about their competence (e.g., Horn \& Weiss, 1991). However, parental appraisals

3 still have influence through adolescence, particularly in the sport domain, because parents

4 are likely to be extensively involved in their children's sport experiences at this age in

5 terms of transporting children, attending games and practices, coaching teams, etc. In

6 contrast to other achievement domains, such as academics, parents have extensive

7 opportunities to convey competence information in the sport and physical activity domain

8 and thus should remain an important significant other. Socialization research to date has

9 focused upon how parents may influence children's self-appraisals but minimal attention

10 has been devoted to understanding the role of reflected appraisals in contributing to

11 children's self-appraisals in the physical domain.

12 To date, only one study has completely tested the reflected appraisal process by

13 assessing the three elements of the model simultaneously (Felson, 1989) and the findings

14 from this study did not support the mediation hypothesis. The present study was designed

15 to examine these relationships more thoroughly and special attention was devoted to

16 methodological concerns because previous studies suffer from limitations identified by

17 Felson $(1989,1993)$. A major problem with most previous work is that investigations have

18 relied on data collected at a single point in time, making directional interpretation

19 problematic. For example, the correlation between actual appraisal of a significant other

20 and the reflected appraisal or self-appraisal can be the result of an influence of the first on

21 the second (i.e., the first postulate of the reflected appraisal process) as much as it could be

22 through the reverse influence. In this regard, a child who has a high self-appraisal of their

23 sport ability can carry out superior sport performance likely to convince other people that

$24 \mathrm{he} / \mathrm{she}$ is good at sport. 
Similarly, if the correlation between reflected appraisals and self-appraisals is in

2 accordance with the reflected appraisal postulates, one could not rule out the alternative

3 interpretation that self-appraisals "cause" reflected appraisals. Individuals may project

4 their own self-perceptions onto others, especially if there is insufficient information to

5 know how others view them. This alternative explanation has been named a "false

6 consensus effect" (e.g., Felson, 1993; Ross, Greene, \& Hoise, 1977), or "projection effect"

7 (e.g., Jussim et al., 1992). To overcome these alternative explanations, longitudinal

8 designs including auto-regressive influence are particularly useful (Felson, 1993;

9 MacCallum \& Austin, 2000).

10 In addition, an omitted variable, such as the individual's performance level, could

11 produce spurious relationships between self-appraisals, reflected appraisals, and the

12 appraisals of significant others. It may be that successful people evaluate themselves more

13 favorably, believe that others evaluate them more favorably, and are actually evaluated by

14 others more favorably. For example, more highly skilled young athletes may believe that

15 they are athletically able and that others think they are good, and others may logically think

16 they are gifted. Thus, if one variable predicts the other ones (for example, if the others'

17 actual appraisals predict others' reflected appraisal and/or individual's self-appraisal) it is

18 perhaps for reasons of a shared standard. For this reason, as recommended by Felson

19 (1993), it is necessary to control for objective measures of ability (like grades or

20 standardized test scores) when one is examining the reflected appraisal process with

21 correlational data.

22 The main hypothesis of this study was that parents' appraisals of their child's sport

23 competence would predict the child's self-appraisals indirectly, as mediated by the

24 reflected appraisal. To test for this mediation hypothesis, three models were compared (see

25 Figure 1) in order to thoroughly examine the three requirements for mediation defined by 
1 Baron and Kenny (1986). The first model reflected by Figure 1 represents a fully mediated

2 (FM) model in which it is hypothesized that parents' appraisals affect reflected appraisals

3 (i.e., Path A) that, in turn, influence children's self-appraisals (i.e., Path B) after controlling

4 for children initial self-appraisals and actual level of ability (as assessed by child's grades

$5 \quad$ in sport and physical education). The second model represents a partially mediated (PM)

6 model in which an additional path was added to the FM model between the parents'

7 appraisals of their child's competence and the child's physical self-appraisals (i.e., Path C).

8 Finally, Model 3 represents an unmediated (NM) model in which parents' appraisals

9 directly predict children's self-appraisal when paths A and B have been deleted. The PM

10 and NM models allow for examination of the third requirement for the mediation effect,

11 namely "when Paths A and B are controlled, a previously significant relation between the

12 independent and dependent variables is no longer significant" (Baron \& Kenny, 1986, p.

13 1176). The NM model allows us to see if Path $\mathrm{C}$ is significant, and the PM model allows us

14 to see if this path is reduced, or is near zero, when Paths A and B have been controlled.

15 We tested these models using a three wave longitudinal design over one school

16 year, in order to allow for a more sensitive test of our specific directional hypotheses. We

17 also used more sophisticated data analytic techniques, specifically structural equation

18 modeling (SEM), than those which have typically been used in previous studies. SEM

19 allows for the examination of hypothesized relations among all of the constructs involved

20 in a model, using a latent representation of those constructs that is less vulnerable to

21 measurement errors such as those that can be encountered in research with child

22 populations (see MacCallum \& Austin, 2000). It might be that the lack of support for the

23 mediation hypothesis found in Felson's study (1989) was attributable to measurement

24 limitations, to the extent that each variable was only assessed with a single item. 
A related focus of this study addresses possible gender differences in the

2 functioning of the reflected appraisal process. Some researchers (e.g., Eccles, Wigfield,

3 Harold, \& Blumenfeld, 1993) have found that mothers have a stronger impact than fathers

4 on children's behavior, beliefs, and attitudes. Other authors (e.g., Bussey \& Bandura,

5 1999) have suggested that a parent's influence may be stronger for a child of the same

6 gender in that sons might be more sensitive to what their fathers think of them and

7 daughters might be more sensitive to what their mothers think of them. Therefore, it is

8 possible that the RA process is different for sons compared to daughters. Thus, a related

9 objective of this study was to test the invariance of the reflected appraisal process across

10 gender.

Method

12 Participants

13 A sample of 147 sixth graders ( 73 boys and 74 girls) enrolled in two different

14 French schools, their mothers $(M$ age $=40.34 \pm 4.61$ years $)$ and fathers $(M$ age $=42.99 \pm$

156.12 years) were the participants in this study. The child participants ranged in age from 10

16 to 13 years old $(M$ age $=11.73 \pm 0.58$ years $)$. The schools were located in a medium size

17 city $(100,000$ inhabitants $)$ in the southeast of France. The participant sample was

18 comprised primarily of middle to upper class families.

19 Procedure

20 Parents and children completed a consent form prior to participating in the study.

21 Data were obtained from questionnaires in three waves during one school year. The first

22 wave (in September 2001) was collected from parents and children. In the second

23 (February 2002) and third (in June 2002) waves, we only collected data from children.

24 Data were collected during the PE class by a Master's degree student familiar with the

25 precautions needed for data collection. Children completed questionnaires in groups of 
1 about 10 individuals in the classroom. After completion of the first-wave questionnaire,

2 children whose parents agreed to participate were given a questionnaire to complete and

3 were asked to return them a week later. Conditions (i.e. groups and location) for

4 completing the questionnaire in Wave 1, 2 and 3 were the same for the children.

5 Measures

Child's perceived physical competence. Child's self-appraisals of competence in

7 physical activity were assessed in Wave 1 and Wave 3 with a 3 -item questionnaire, similar

8 to the one developed by Nicholls and colleagues (e.g., Duda \& Nicholls, 1992).

9 Participants were asked to answer questions such as "when you are playing sport and

10 physical activity ${ }^{1}$, you consider yourself..." on 7-point scales anchored by "very bad" (1)

11 and "very good" (7). This scale has demonstrated good construct validity, internal

12 consistency and predictive validity in previous studies (e.g., Sarrazin, Roberts, Cury,

13 Biddle, \& Famose, 2002; Trouilloud, Sarrazin, Martinek, \& Guillet, 2002).

Parents' appraisals of their child's physical competence. During Wave 1, mothers and fathers completed a French version of the Jacobs and Eccles' (1992) questionnaire on parents' appraisals of their child's competence. The back-translation method (see Brislin, 1986) was used to translate the original scale into French. This 3 -item scale is comprised of questions such as "In general how good is your child in sports?" Each item was rated on a scale from 1 = "not at all good" through 7 = "very good." In previous research, this scale has been found to be valid and reliable (e.g., Bois et al., 2002). Reflected appraisal of parents. Children's reflected appraisal of parents was assessed distinctly for mothers and fathers at Wave 2, with a six-item questionnaire similar to the one developed by Amorose (e.g., 2002). Specifically, three items for each parent tapped the extent to which children thought that their mother and their father considered them physically competent. The items were designed to match the ones used in assessing 
1 parents' appraisals of their child's competence (e.g., "How good does your mother/father

2 think you are at sports"). The child responded according to a 7-point scale with higher

3 scores reflecting more positive reflected appraisals.

4

Child's physical education grade. In France, all students from the sixth through

5 the twelfth grades take mandatory sport and physical education classes. Each student is

6 graded at the end of each term on a scale ranging from 0 to 20 . We collected the teacher's

7 evaluation of the participating students for the first term (i.e., from September to

8 December, before the assessment of Wave 2 variables).

9 Data Analysis

10 Preliminary data analyses and descriptive statistics were performed before testing

11 the hypotheses. First, a confirmatory factor analysis (CFA) was conducted to examine the

12 construct validity of the variables in the study. Then, SEM was used to test relations

13 among the variables as hypothesized in the three models of Figure 1. To investigate the

14 issue of mediation, the requirements advocated by Baron and Kenny (1986) were carefully

15 examined. A chi-square difference test between the PM and FM models was carried out to

16 see whether the global fit is improved by including the path $\mathrm{C}$. If this were the case, the

17 chi-square difference between the two models should be significant and would mean that

18 the mediation of the reflected appraisal is not complete. Subsequently multi-sample

19 analysis was used to assess the invariance of the model across gender of the child.

Results

Descriptive Statistics and Preliminary Analyses

Results from descriptive statistics of all indices under study revealed that the data were normally distributed with values for skewness and kurtosis within an acceptable range of -1.0 to +1.0 . Seven participants (less than $5 \%$ of the sample) did not provide 
1 complete responses to questionnaires and their responses were not included in the data

2 analysis.

Table 1 presents the Cronbach alphas reflecting internal reliability of the scales as

4 well as the means and standard deviations of the variables included in the study. A

5 MANOVA was conducted to investigate possible gender differences on variables of

6 interest. Results revealed a marginally significant main effect, Wilks' lambda $=.92, R(6$,

$7140)=2.06, p=.062$. Follow-up univariate ANOVAS indicated only two gender

8 differences in that boys had higher scores than girls on self-appraisal at Time $1(F(1,145)$

$\left.9=9.21, p<.01, \eta^{2}=.06\right)$ and at Time $3\left(F(1,145)=5.31, p<.05 ; \eta^{2}=.04\right.$, see group

10 means in Table 1). To test whether parents' appraisals of their child's competence varied

11 as a function of their own or their child's gender, a 2 (child's sex) $\times 2$ (parent's sex)

12 analysis of variance was conducted, with repeated measures on the last variable. Neither

13 main effects nor significant interactions were present in this analysis.

To examine the construct validity of the measures included in the study, a

16 confirmatory factor analysis was conducted. On the first step of this analysis a model based

17 on six latent constructs (i.e., child perceived competence at Wave 1 and Wave 3, mothers'

18 appraisals, fathers' appraisals, reflected appraisals of mother and father) and 18 observed

19 variables (individual items from each questionnaire) was tested. The analysis was

20 conducted with LISREL 8.3 (Jöreskog \& Sörbom, 1996) using a covariance matrix ${ }^{2}$ and

21 maximum likelihood method of estimation. In view of the current controversy regarding measures of overall goodness of fit, it is generally considered appropriate to report multiple

23 indices of fit (Bollen, 1989). Thus, the chi-square statistic, the non-normed fit index

24 (NNFI), the comparative fit index (CFI) and the standardized root mean square residual

25 (SRMR) all were used to evaluate the adequacy of the fit of the model to the data. For the 
1 NNFI and CFI, values above .90 are considered satisfactory. For SRMR, values below .10

2 indicate a good fit of the model to the data.

This first model presented a poor fit to the data: $\chi^{2}(120, N=147)=364.34, p<$ $.001, \mathrm{NNFI}=.72, \mathrm{CFI}=.78, \mathrm{SRMR}=.08$. Analysis of the output revealed large residuals between the three indicators of mothers' and fathers' reflected appraisals. As the questions for reflected appraisals of mothers and fathers were the same (only the word "mother" or "father" differed) some children may have answered the same way for mothers and fathers on this variable. Hence we decided to add three covariance errors between the three indicators of mothers' reflected appraisals and the three indicators of fathers' reflected appraisal. This modification resulted in a significant improvement of the fit of the model: $\chi^{2}(117, N=147)=185.08, p<.001, \mathrm{NNFI}=.94, \mathrm{CFI}=.96, \mathrm{SRMR}=.05$. The correlations between all the variables were low to moderate except for the correlation between mothers' and fathers' appraisals of their child's competence $r=.79$ ) on one hand and between reflected appraisals of mothers and fathers $(r=.99)$ on the other hand. Therefore, we decided to test the discriminant validity of these constructs. We examined whether each of those two pairs of latent factors could be treated as a single construct by setting each correlation to 1.0 and comparing the constrained model to the original one in which the correlation was free to be estimated (see Anderson \& Gerbing, 1988). This test was performed separately for each pair of latent construct. Chi-square difference tests indicated that the models with the correlation set to 1.0 were not different from the model freely estimated $(p s>10)$. Therefore mothers' and fathers' appraisals of their child's ability on one hand, and the child's reflected appraisals of mothers and fathers on the other hand were combined to form two factors (in place of four) based on six observed variables each. The first term was labeled "parents' appraisals of their child's perceived competence" and the second was labeled "reflected appraisals of parents." The new four- 
1 factor model presented an adequate fit to the data: $\chi^{2}(126, N=147)=222.7, p<.001$,

$2 \mathrm{NNFI}=.93, \mathrm{CFI}=.94, \mathrm{SRMR}=.05$ and was used in the subsequent analyses ${ }^{4}$. The

3 construct reliability ${ }^{3}$ of the four factors were $\rho=.82, .87, .84, .82$, respectively for

4 children's self-appraisals at Wave 1, parents' perceptions of their child competence,

5 parents' reflected appraisal and children's self-appraisals at Wave 3.

6 Comparison of Structural Models

Since the validity of the factor structure was confirmed, the hypothesized relationships between the four latent variables and the child's grade (considered as a manifest variable) were estimated and the three proposed models (see Figure 1) were tested.

The FM model presented an adequate fit to the data: $\chi^{2}(141, N=147)=229.25, p<$ $.001, \mathrm{NNFI}=.93, \mathrm{CFI}=.95, \mathrm{SRMR}=.05$. The structural and measurement coefficients of this model are presented in Figure 2. Parents' appraisals significantly predicted reflected appraisals $(\gamma=.52, p<.001)$ independent of the effects of children's initial self-appraisals children self-appraisals at Time $3(\beta=.44, p<.001)$, independent of children initial selfappraisals $(\gamma=.39, p<.001)$ and grades $(\gamma=.12, p>.05)^{5}$. This model accounted for 59 percent of the variance of the child's self-appraisals at Time 3.

PM model presented an adequate fit to the data: $\chi^{2}(140, N=147)=229.24, p<$ $.001, \mathrm{NNFI}=.93, \mathrm{CFI}=.94, \mathrm{SRMR}=.05$. Nevertheless, the effect of parents' appraisals on child's self-appraisals at Time 3 (i.e., Path C) was nonsignificant $(\gamma=.01, p>.05)$. This model account for 59 percent of the variance of the child's self-appraisals at Time 3 . The comparison between the PM and FM models suggested that the addition of the Path $\mathrm{C}$ did not significantly improve the fit $\left[\Delta \chi^{2}(1)=.01, p>.05\right]$, hence the simplest model (i.e., the 
$2=244.06, p<.001, \mathrm{NNFI}=.92, \mathrm{CFI}=.94, \mathrm{SRMR}=.064$. Parents' appraisals significantly

3 predicted their child's self-appraisals at Time $3(\gamma=.26, p<.05)$ independent of the

4 effects of children's initial self-appraisals $(\gamma=.47, p<.001)$ and grades $(\gamma=.12, p>.05)$.

5 This model accounted for 50 percent of the variance of the child's self-appraisals at Time $6 \quad 3$ Inspection of the relevant parameters indicated that the three criteria for mediation

8 listed by Baron and Kenny (1986) were fully achieved: (1) parents' appraisals significantly

9 influenced reflected appraisals (i.e., Path A; $\gamma=.52, p<.001)$; (2) reflected appraisals of

10 parents significantly predicted the child's final self-appraisals (i.e., Path B; $\gamma=.44, p$

$11<.001)$; and (3) the direct path from parents' appraisals to child's self-appraisals (i.e., Path

12 C) was nonsignificant when Paths A and B were controlled for $(\gamma=.01, p>.05$, in the PM

13 model), whereas this path was significant $(\gamma=.26, p<.05)$ when the Paths A and B were

14 removed (in the NM model).

15 Multigroup analyses

16 A multi-group analysis was conducted to test invariance of the FM model across

17 gender. This involved testing to determine if setting the parameters to be equal across

18 gender produced a significant change in chi-square compared to the free-constraint model.

19 The free-constraint model represents a model in which parameters of the boys' and girls'

20 models are evaluated without any between-group constraints. The results demonstrated that

21 constraining the parameters did not significantly decrease the fit of the model $[\Delta \chi 2(6)=$

$228.73, p>.05]$, which suggests that the processes involved in the model appear to be similar 23 across gender. 
The goal of this study was to examine the role of the reflected appraisal process

2 between parents and sixth graders in the ontogeny of children's self-appraisals of physical

3 competence. Reflected appraisals may constitute an important dimension of the sport and

4 physical activity socialization process and a primary purpose of this study was to extend

5 the current knowledge base on sport socialization influence by systematically evaluating

6 the role of reflected appraisals on children's self-appraisal of sport competence.

7 Preliminary findings and issues dealing with the validity of our model will be discussed

8 before addressing the question of the reflected appraisal process per se.

$9 \quad$ Preliminary Findings

10 Preliminary analyses revealed marginally significant gender differences, with boys

11 having greater perceived competence than girls, both at Wave 1 and at Wave 3 . Those

12 findings are consistent with numerous previous studies (e.g., Bois et al., in press, 2002;

13 Dempsey et al., 1993; Eccles \& Harold, 1991), which have found that boys tend to be more

14 confident in their physical abilities than are girls. On the other hand, parents' appraisals of

15 their child's competence did not vary in relation to the child's gender. This finding is

16 consistent with some recent studies (e.g., Bois et al., in press, 2002; Kimiecik \& Horn,

17 1998) but not with some others (e.g., Eccles, Jacobs, \& Harold, 1990; Jacobs \& Eccles,

18 1992) which have found a differentiation in parents' expectancies in relation to the child's 19 gender.

A confirmatory factor analysis indicated that mothers' and fathers' appraisals of

21 their child's competence were strongly related. Although some authors (e.g., Brustad et

22 al., 2001) have argued that the two parents might not share similar appraisals of their

23 child's ability, we are not aware of studies that have found substantial parental differences

24 in ability appraisals. It was also found through the CFA that the reflected appraisals of

25 parents were not appreciably different between mothers and fathers. This finding suggests 
1 that children of this age do not distinguish between their mother's and their father's

2 appraisals of them. This finding is in accordance with other studies (Amorose, 2003;

3 Felson, 1989) that have found that children were more influenced by a generalized other

4 (e.g., parents or sport others) than by a distinctly perceived significant other. However this

5 finding was not surprising given that mothers' and fathers' ability perceptions were not

6 highly differentiated. Hence, children in this sample may not distinguish between mothers'

7 and fathers' evaluations of their competence because those appraisals are not actually

8 different. These findings considered together seem to be consistent with the hypothesis

9 from symbolic interactionist theory (Felson, 1993; Mead, 1934) that individuals have a

10 better idea of how they are viewed by collective others than how they are viewed by

11 individual others alone.

12 Reflected Appraisal Process

13 The main hypothesis of this study was that reflected appraisals mediate the effect of 14 parents' appraisals on children's self-appraisals of physical competence. According to 15 Baron and Kenny (1986), providing support for this mediation effect required: (1) a link 16 between parents' appraisals and reflected appraisals; (2) a link between reflected appraisals 17 and children's self-appraisals; (3) a significant decrease in the path between parents' 18 appraisals and children self-appraisals after the first two links had been controlled. In relation to the first point it was hypothesized that parents' appraisals would have positive effects on the child's reflected appraisals of parents, controlling for actual level of 21 ability in sport as well as prior level of self-appraisals. The effect of initial level of selfappraisals on later reflected appraisals is called the projection effect (e.g., Jussim et al., 1992) or "false consensus effect" (e.g., Felson, 1993; Ross et al., 1977) and refers to the processes whereby individuals can base their reflected appraisals from others on their own self-views rather than on what others think of them (e.g. Jussim et al., 1992; Tice \& 
1 Wallace, 2003). In other words, people's inferences on how they are appraised by others

2 may be based on their self-views rather than on an accurate understanding of how others

3 actually see them especially if there is insufficient information to know how others view

4 them.

Our results (see Figure 2) lend support to an effect of parents' appraisals on

6 children's reflected appraisal $(\gamma=.52, p<.001)$ and don't provide evidence for the

7 projection effect $(\gamma=.17, p>.05)$. The significant influence of parents' appraisals on

8 children's reflected appraisals indicates that children are rather accurate in perceiving their

9 parents' appraisals. This finding is controversial to the extent that it does not support most

10 of the recent work in this line of research that has found that people are not very accurate

11 in identifying what significant others think of them (Felson, 1993; Shrauger \&

12 Schoeneman, 1979; Tice \& Wallace, 2003). But how can one explain that the youngsters in

13 this study were more accurate than participants in previous studies in identifying

14 significant others' appraisals of their abilities? Two explanations can be provided. First, we

15 investigated the accuracy of the appraisal between children and parents. Some investigators

16 (Malloy et al., 1997) have found that people are more accurate in guessing how they are

17 viewed by family members than by other people (i.e. friends or coworkers). Moreover, as

18 children in our sample are relatively young they are likely to be more attuned to their

19 parents' judgments than to other significant others, such as peers. Hence the close

20 relationship between parents and children at this age may explain those results.

21 However, it can also be emphasized that the methodology used in this study with

22 data collected at three points in time combined with structural equation modeling may

23 contribute to the explanation of these results. In particular, the fact that measurement error

24 is partly controlled for by SEM may have provided a more thorough test of the hypotheses

25 in this study than in previous studies. This sort of methodology (i.e. combining SEM and 
1 longitudinal data) had not been used in the previously cited studies. Hence the difference in

2 the pattern of results might arise from this analytical strategy. In comparison to previous

3 studies, our results demonstrated a relatively high accuracy of reflected appraisals, in

4 contrast to what has been found in the past (Felson, 1993; Tice \& Wallace, 2003) but has

5 casts doubt on the presence of the projection effect. Further longitudinal studies are

6 needed to disentangle the relationships among those variables.

7 The second point hypothesized that the reflected appraisals of parents would have

8 positive effects on children's self-appraisals, independent of the child's initial self-

9 appraisals and the child's actual level of ability in sport. The results support this

10 hypothesis. The fact that reflected appraisals and self-appraisals are significantly related is

11 acknowledged in the literature (e.g. Babkes \& Weiss, 1999; Felson, 1993). However our

12 results show only a moderate relationship between reflected appraisals and self-appraisals.

13 Hence, even though children are rather accurate in perceiving what their parents think of

14 them, they don't completely base their self-views on these perceptions. It is likely that

15 numerous significant others, such as peers, coaches or teammates are involved in this

16 process as has been hypothesized by Amorose (2003). Further studies that extend the

17 number of significant others investigated are needed to get a better understanding of the

18 role of social influences in the development of children's self-appraisals.

19 It was also proposed that the magnitude of the influence of parents' appraisals on

20 children's self-appraisals would be reduced when reflected appraisals had been controlled

21 for. The results supported this expectation. In the NM model, the path from parents'

22 appraisals to children's self-appraisals was significant $(\gamma=.26, p<.05)$ although it was

23 nonsignificant in the PM model $(\gamma=.01, p>.05)$ where the influence of reflected

24 appraisals on self-appraisals was controlled for and significant $(\beta=.43, p<.01)$.

25 Subsequent analyses led us to prefer the FM model (see Figure 2) which was more 
1 parsimonious and powerful in terms of variance explained in the dependent variable. To

2 our knowledge, this study is the first conducted in a natural setting that fully demonstrates

3 the three hypothesized steps in the reflected appraisal process. Previous studies either only

4 partially tested this process (e.g. Amorose, 2002, 2003), or failed to demonstrate the

5 mediation effect (e.g. Felson, 1989). The fact that our results are not consistent with

6 Felson's study is intriguing. However two methodological points might explain those

7 discrepancies. First, all of the constructs involved in Felson's study (1989) were assessed

8 using only a single item. This could have caused some measurement difficulties. Second,

9 the sample used in the Felson study (1989) covered a broader age range (fourth through

10 seventh grade children) than our sample of sixth grade children. We are aware that as

11 children get older they become increasingly able to use others' appraisals to estimate their

12 physical competence (e.g., Horn \& Amorose, 1998). Therefore, the mediational process

13 identified in our study might have been masked in Felson's study because younger and

14 older children were included in the same sample.

15 We also investigated the invariance of the reflected appraisal process across gender.

16 The goal of this analysis was to test whether parental influence through the reflected

17 appraisal process could vary as a function of the child's gender. The multigroup analysis

18 revealed no significant differences in the model between boys and girls. This seems to

19 indicate that the process does not differ between boys and girls. However, other individual

20 difference factors such as age or level of involvement in sport may influence the reflected

21 appraisal process and could constitute a new area of investigation.

22 Special attention was dedicated to the methodology used in this study; however

23 some limitations have to be acknowledged. First, although we used a longitudinal design to

24 enhance directional inferences that can be drawn from our data, the findings remain

25 correlational in nature and therefore must be interpreted cautiously. Due to the use of a 
1 longitudinal design we can be sure that the variables assessed at the start of the year were

2 not caused by the ones assessed ten months later, but it is always possible that an omitted

3 variable is the origin of a link found between a predictor variable and an outcome variable.

4 Nevertheless, including the variables of the child's physical education grade and the

5 child's initial level of perceived competence limits the likelihood that this occurred.

6 Secondly, the use of grades as an indication of the child's actual physical ability may

7 constitute another limitation of the study. As emphasized by Jussim (1991), marks can be

8 biased by the teacher's beliefs or a priori opinion. Furthermore, the fact that grades are

9 often specific to a limited range of physical activities may reflect that they do not entirely

10 capture the overall physical competence of the child. These two points can explain why

11 grades did not predict reflected appraisals and self-appraisals. However using grades as an

12 objective indicator of ability also enhanced the quality of the study as it enabled us to

13 control for, to some extent, the actual physical ability of the child. A third limitation of the

14 study pertains to the independence of mothers' and fathers' responses. As no specific

15 mechanism was used to ensure that each parent completed his/her questionnaire

16 independently from the other, it is possible that some of the parents completed the

17 questionnaires together.

18 In sum, this study has demonstrated a link between parents' appraisals and the

19 reflected appraisals of ability in the sport domain held by their children. Secondly, a link

20 was found between reflected appraisals and self-appraisals that is consistent with symbolic

21 interactionist perspectives (Cooley, 1902; Mead, 1934) and certain empirical studies

22 (Amorose, 2002, 2003; Babkes \& Weiss, 1999). This result cannot be explained by a

23 projection effect, a concurrent hypothesis to the reflected appraisal process that has been

24 mentioned by some authors (e.g. Felson, 1989, 1993; Tice \& Wallace, 2003), since the

25 projection effect was controlled for. Finally, this study supports the mediation of parents' 
1 appraisal effects on child's self-appraisals by reflected appraisals although this relation has

2 not been previously supported (Felson, 1989).

3 From a pragmatic view, these results emphasize the importance of the interpretation

4 that children can make about their parents' beliefs and behaviors and helps to further the

5 knowledge base on parental socialization effects in the physical domain. Parents should be

6 aware not only of what they do and say to their children, but also of the way children

7 understand, perceive and interpret those beliefs and behaviors as it affects their subsequent

8 motivation. In terms of positive outcomes, parents may promote positive reflected

9 appraisals and self-appraisals, positive expectancies, and encouragement and thus

10 contribute to their children's successful involvement in physical activity and sport. 
2 Anderson, J.C., \& Gerbing D.W. (1988). Structural equation modeling in practice: A review and recommended two-step approach. Psychological Bulletin, 103, 411-423.

4 Amorose, A. J. (2002). The influence of reflected appraisals on middle school and high school athletes' self-perceptions of sport competence. Pediatric Exercise Science, 14, 377-390.

7 Amorose, A. J. (2003). Reflected appraisals and perceived importance of significant others' appraisals as predictors of college athletes self-perceptions of competence. Research Quarterly for Exercise and Sport, 74, 60-70.

Babkes, M. L., \& Weiss, M. R. (1999). Parental influence on children's cognitive and affective responses to competitive soccer participation. Pediatric Exercise Science,

13 Baron, R. M., \& Kenny, D. A. (1986). The moderator-mediator variable distinction in social psychological research: conceptual, strategic and statistical considerations. Journal of Personality and Social Psychology, 51, 1173-1182.

Bois, J. E., Sarrazin, P. G., Brustad, R. J., Trouilloud, D. O., \& Cury, F. (2002). Mothers' expectancies and young adolescents' perceived physical competence: a yearlong study. Journal of Early Adolescence, 22, 384-406.

Bois, J. E., Sarrazin, P. G., Brustad, R. J., Trouilloud, D. O., \& Cury, F. (in press). Elementary schoolchildren's perceived competence and physical activity involvement: The influence of parents' role modelling behaviours and perceptions of their child's competence. Psychology of Sport and Exercise.

23 Bollen, D. A. (1989). Structural equations with latent variables. New York: Wiley. 
1 Brislin, R.W. (1986). The wording and translation of research instruments. In W. Lonner \& J. Berry (Eds.), Field methods in cross-cultural research (pp. 137-164). Beverly Hills, CA: Sage.

4 Brustad, R. J. (1993). Who will go out and play? Parental and psychological influences on children's attraction to physical activity. Pediatric Exercise Science, 5, 210-223.

Brustad, R. J. (1996). Attraction to physical activity in urban schoolchildren: Parental socialization and gender influences. Research Quarterly for Exercise and Sport, 67, 316-323.

Brustad, R. J., Babkes, M. L., \& Smith, A. L. (2001). Youth in sport: Psychological considerations. In R. N. Singer, H. A. Hausenblas, \& C. M. Janelle (Eds.) Handbook of sport psychology, (2 ${ }^{\text {nd }}$ ed., pp. 604-635). New York: Wiley.

12 Bussey, K., \& Bandura, A. (1999). Social cognitive theory of gender development and differentiation. Psychological Review, 106, 676-713.

14 Cooley, C. H. (1902). Human, nature and the social order. New York: Scribner's.

Deci, E. L., \& Ryan, R. M. (2000). The "what" and "why" of goal pursuits: human needs and the Self-Determination of behaviour. Psychology Inquiry, 11, 227-268

Dempsey, J. M., Kimiecik, J. C., \& Horn, T. S. (1993). Parental influence on children's moderate to vigorous physical activity participation: An expectancy-value approach. Pediatric Exercise Science, 5, 151-167.

Duda, J. L, \& Nicholls, J. G. (1992). Dimension of achievement motivation in schoolwork and sport. Journal of Educational Psychology, 6, 334-343.

Eccles J. S., \& Harold, R. D. (1991). Gender differences in sport involvement: Applying the Eccles' expectancy-value model. Journal of Applied Sport Psychology, 3, 7-35. 
1 Eccles, J. S., Jacobs, J. E., \& Harold, R. D. (1990). Gender role stereotypes, expectancy

2 effects, and parents' socialization of gender differences. Journal of Social Issues, 46, 183-201.

4 Eccles, J. S., Wigfield, A., Harold, R. D., \& Blumenfeld, P. (1993). Age and gender differences in children's self and task perceptions during elementary school. Child Development, 64, 830-847.

7 Eccles, J. S., Wigfield, A, \& Shiefele, U. (1998). Motivation to succeed. In N. Eisenberg (Ed.) and W. Damon (Series Ed.), Handbook of child psychology: Vol. 3 Social, emotional, and personality development (5 ${ }^{\text {th }}$ ed., pp. 1051-1071). New York: Wiley.

10 Elliot, A.J., \& Church, M.A. (1997). A hierarchical model of approach and avoidance achievement motivation. Journal of Personality and Social Psychology, 72, 218-232.

Felson, R. B. (1989). Parents and the reflected appraisal process: A longitudinal analysis. Journal of Personality and Social Psychology, 56, 965-971.

Felson, R. B. (1993). The (somewhat) social self: How others affect self-appraisals. In J.

Felson, R. B., \& Reed, M. (1986). The effect of parents on the self-appraisals of children. Social Psychology Quarterly, 49, 302-308.

Frieze, I., \& Bar-Tal, D. (1980). Developmental trends in cue utilization for attributional judgments. Journal of Applied Developmental Psychology, 1, 83-94.

Frome, P. M., \& Eccles, J. S. (1998). Parents' influence on children's achievement-related perceptions. Journal of Personality and Social Psychology, 74, 435-452. psychology (pp. 201-218). Champaign, IL: Human Kinetics. 
1 Harter, S. (1981). A model of mastery motivation in children: Individual differences and

2 developmental change. In A. Collins (Ed.), Minnesota Symposium on Child

3 Psychology: Vol. 14 (pp. 215-225). Hillsdale, NJ: Erlbaum.

4 Harter, S. (1998). The development of self-representations. In N. Eisenberg (Ed.), Handbook of child psychology: Volume 3, Social, emotional and personality development (pp. 553-618). New York: John Wiley \& Sons.

Horn, T. S., \& Amorose, A. J. (1998). Sources of competence information. In J. L. Duda (Ed.), Advances in Sport and Exercise Psychology Measurement (pp. 49-63). Morgantown, WV: Fitness Information Technology.

Horn, T. S., \& Harris, A. (1996). Perceived competence in young athletes: Research findings and recommendations for coaches and parents. In F.L. Smoll \& R.E. Smith (Eds.), Children and youth in sport (pp. 309-329). Chicago: Brown \& Benchmark.

Horn, T.S., \& Weiss, M.R. (1991). A developmental analysis of children's self-ability judgments in the physical domain. Pediatric Exercise Science, 3, 310-326.

Ichiyama, M.A. (1993). The reflected appraisal process in small-group interaction. Social Psychology Quarterly, 56, 87-99.

Jacobs, J. E., \& Eccles, J. S. (1992). The impact of mothers' gender role stereotypic beliefs on mothers' and children's ability perceptions. Journal of Personality and Social Psychology, 63, 932-944.

Jöreskog, K., \& Sörbom, D. (1996). Lisrel 8 : User's reference guide. Chicago: SSI inc. Judd, C. M., \& McClelland, G. H. (1989). Data analysis model comparison approach. Orlando, FL: Harcourt Brace Jovanovich.

Jussim, L. (1991). Grades may reflect more than performance: Comment on Wentzel (1989). Journal of Educational Psychology, 83, 153-155. 
1 Jussim, L., Soffin, S., Brown, R., Ley, J., \& Kohlhepp, K. (1992). Understanding reactions

2 to feedback by integrating ideas from symbolic interactionism and cognitive

3 evaluation theory. Journal of Personality and Social Psychology, 62, 402-421.

4 Kimiecik, J. C., Horn, T. S., \& Shurin, C. S. (1996). Relationships among children's beliefs, perceptions of their parents' beliefs and their moderate to vigorous physical activity. Research Quarterly for Exercise and Sport, 67, 324-336.

7 Kimiecik, J. C., \& Horn, T. S. (1998). Parental beliefs and children's moderate-to-vigorous physical activity. Research Quarterly for Exercise and Sport, 69, 163-175.

9 Kinch, J. W. (1963). A formalized theory of self-concept. American Journal of Sociology, $68,481-486$.

MacCallum, R. C., \& Austin, J. T. (2000). Applications of structural equation modeling in psychological research. Anmual Review of Psychology, 51, 201-226.

Malloy, T.E., Albright, L., Kenny, D.A., Agatstein, F., \& Winquist, T. (1997). Interpersonal perception and metaperception in nonoverlapping social groups. Journal of Personality and Social Psychology, 72, 390-398.

Mead, G. H. (1934). Mind, self, and society. Chicago: University of Chicago Press.

Parsons, J., Adler, T., \& Kaczala, C. (1982). Socialization of achievement attitudes and perceptions: Parental influences. Child Development, 53, 310-329.

Phillips, D. (1987). Socialization of perceived academic competence among highly competent children. Child Development, 58, 1308-1320.

Ross, L., Greene, D., \& House, P. (1977). The "false consensus effect": An egocentric bias in social perception and attribution processes. Developmental Psychology, 13, 279301.

24 Sarrazin, P. G., Roberts, G. C., Cury F., Biddle, S. J., \& Famose, J. P. (2002). Exerted effort and performance in climbing among boys: The influence of achievement goals, 
perceived ability, and task difficulty. Research Quarterly for Exercise and Sport, 73, $425-436$.

Shrauger, J.S., \& Schoeneman, T.J. (1979). Symbolic interactionist view of self-concept: Through the looking glass darkly. Psychological Bulletin, 86, 549-573.

Stipek, D., \& Mac Iver, D. (1989). Developmental change in children's assessment of intellectual competence. Child Development, 60, 521-538.

Swann, W., Milton, L., \& Polzer, J. (2000). Should we create a niche or fall in line? Identity negotiation and small group effectiveness. Journal of Personality and Social Psychology, 79, 238-250.

Tice, D.M., \& Wallace, H.M. (2003). The reflected self: Creating yourself as (you think) others see you. In M.R. Leary \& J.P. Tangney (Eds.), Handbook of self and Identity (pp. 91-105). New York: The Guilford Press.

Trouilloud, D., Sarrazin, P., Martinek, T., \& Guillet, E. (2002). The influence of teacher's expectations on students' achievement in physical education classes: Pygmalion revisited. European Journal of Social Psychology, 32, 591-607.

Weiss, M. R. \& Ebbeck, V. (1996). Self-esteem and perceptions of competence in youth sport: Theory, research, and enhancement strategies. In O. Bar-Or (Ed.), The encyclopedia of sports medicine, Vol. V: The child and adolescent athlete (pp. 364382). Oxford: Blackwell Scientific Publications, Ltd.

Weiss, M. R., Ebbeck, V., \& Horn, T. S. (1997). Children's self-perceptions and sources of competence information: A cluster analysis. Journal of Sport \& Exercise Psychology, 19, 52-70.

Weiss, M.R, \& Ferrer-Caja, E. (2002). Motivational orientations and sport behavior. In T.S. Horn (Ed.), Advances in sport Psychology (2 ${ }^{\text {nd }}$ Edition) (pp. 101-183). Champaign, IL: Human Kinetics. 
Author Notes

Julien E. Bois, Philippe Sarrazin, Julien P. Chanal, and David O. Trouilloud, Laboratory "Sport et Environnement Social”, University J. Fourier Grenoble 1, France; Robert J. Brustad, School of Sport and Exercise Science, University of Northern Colorado. Julien E. Bois is now at the "Laboratoire d'Analyse de la Performance Sportive", Université de Pau et des Pays de l'Adour, France. This study was facilitated by a grant from two French sport organizations: the 'Direction Départementale de la Jeunesse et des Sport 26' and the 'Comité Départemental Olympique et Sportif de la Drôme'. We thank Virginie Nicaise who helped in the data collection of the study.

Correspondence concerning this article should be addressed to Philippe Sarrazin, "Laboratoire Sport et Environnement Social" E.A. 3742, UFRAPS, Université J. Fourier, Grenoble I. BP 5338041 Grenoble Cedex 9, France. E-mail: philippe.sarrazin@ujfgrenoble.fr or julien.bois@univ-pau.fr. 
2 1. We used alternatively the terms "sport" or "physical activity", because in France the two

3 have a very similar meaning and designate all forms of exercise and leisure-time physical

4 activity.

5 2. The covariance matrix used for this analysis is available upon request to the second

6 author.

7 3. Reliability estimates for the total scales are obtained by (Bollen, 1989): $\rho=(\Sigma \lambda i)^{2} /$

$8\left((\Sigma \lambda i)^{2}+\Sigma \delta\right.$ ii) where $\lambda \mathrm{i}$ are the factor loading and $\delta$ ii the error variances.

9 4. Omission of the three error covariance between measurement error of indicators of

10 reflected appraisal resulted in a poorer fit of the model: $\chi^{2}(129, N=147)=425,24, p<$

$11.001, \mathrm{NNFI}=.71, \mathrm{CFI}=.76, \mathrm{SRMR}=.09, \Delta \chi^{2}(\mathrm{df}=3)=202,5, p<.001$. To the extent that

12 the same person (i.e. the child) answers to questions where only the word "father" or

13 "mother" change, the error covariance has to be seen as method variance due to the

14 similarity of the items.

15 5. Omission of the three insignificant paths did not significantly alter the fit of this model:

$16 \chi^{2}(144, N=147)=231.92, p<.001, \mathrm{NNFI}=.93, \mathrm{CFI}=.94, \mathrm{SRMR}=.06$. 
3 Table 1

4

5 Cronbach alpha, mean ratings, standard deviations and correlations of children and 6 parents variables.

7

\begin{tabular}{|c|c|c|c|c|c|c|c|c|c|c|c|}
\hline \multirow[b]{2}{*}{ Variables } & \multirow[b]{2}{*}{$\alpha$} & \multicolumn{2}{|c|}{ Girls } & \multicolumn{2}{|c|}{ Boys } & \multirow[t]{2}{*}{1} & \multirow[t]{2}{*}{2} & \multirow[t]{2}{*}{3} & \multirow[t]{2}{*}{4} & \multirow[t]{2}{*}{5} & \multirow[t]{2}{*}{67} \\
\hline & & $M$ & $S D$ & $M$ & $S D$ & & & & & & \\
\hline 1. Grade & - & 13.05 & 2.11 & 13.4 & 2.75 & - & & & & & \\
\hline 2. Child's self-app & .82 & 5.03 & 1.05 & 5.59 & 1.16 & .29 & - & & & & \\
\hline 3. Mothers' appraisals & .79 & 4.67 & 1.00 & 4.71 & 1.10 & .42 & .44 & - & & & \\
\hline 4. Fathers' appraisals & .81 & 4.67 & 1.04 & 4.70 & 1.13 & .39 & .40 & .66 & - & & \\
\hline 5. Reflected appraisal o & .75 & 4.78 & 1.14 & 4.96 & 1.10 & .30 & .35 & .47 & .50 & 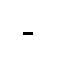 & \\
\hline 6. Reflected appraisal of fathers & .74 & 4.73 & 1.16 & 4.92 & 1.16 & .32 & .38 & .50 & .53 & .94 & - \\
\hline 7. Child's self-appraisals (Wave 3 ) & .81 & 5.01 & 1.24 & 5.45 & 1.04 & .35 & .53 & .42 & .43 & .55 & .53 \\
\hline
\end{tabular}

8 Notes. $N=147$. All correlations are significant: $p<.05$

9

10

11

12 
2 Figure Caption.

3

4

5

6

7

8

9

10 Figure 2. Structural equation model of the fully mediated model. Standardized solutions

11 are presented. $* * p<.01 \quad * * * p<.001$
Figure 1. Series of tested models. From top to bottom: fully mediated model (FM), partially mediated model (PM), and non-mediated model (NM). 
Wave 1

1

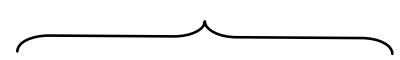

Wave 2

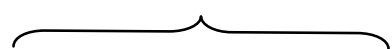

Wave 3

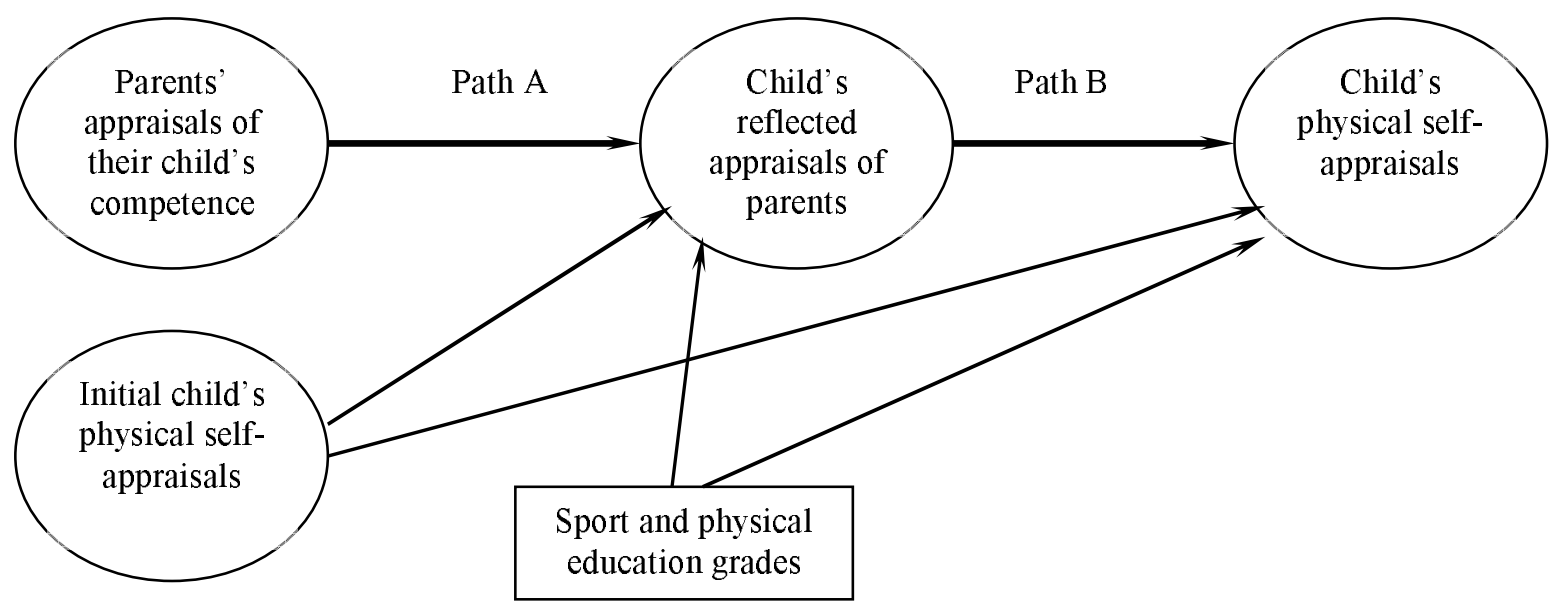

Path C
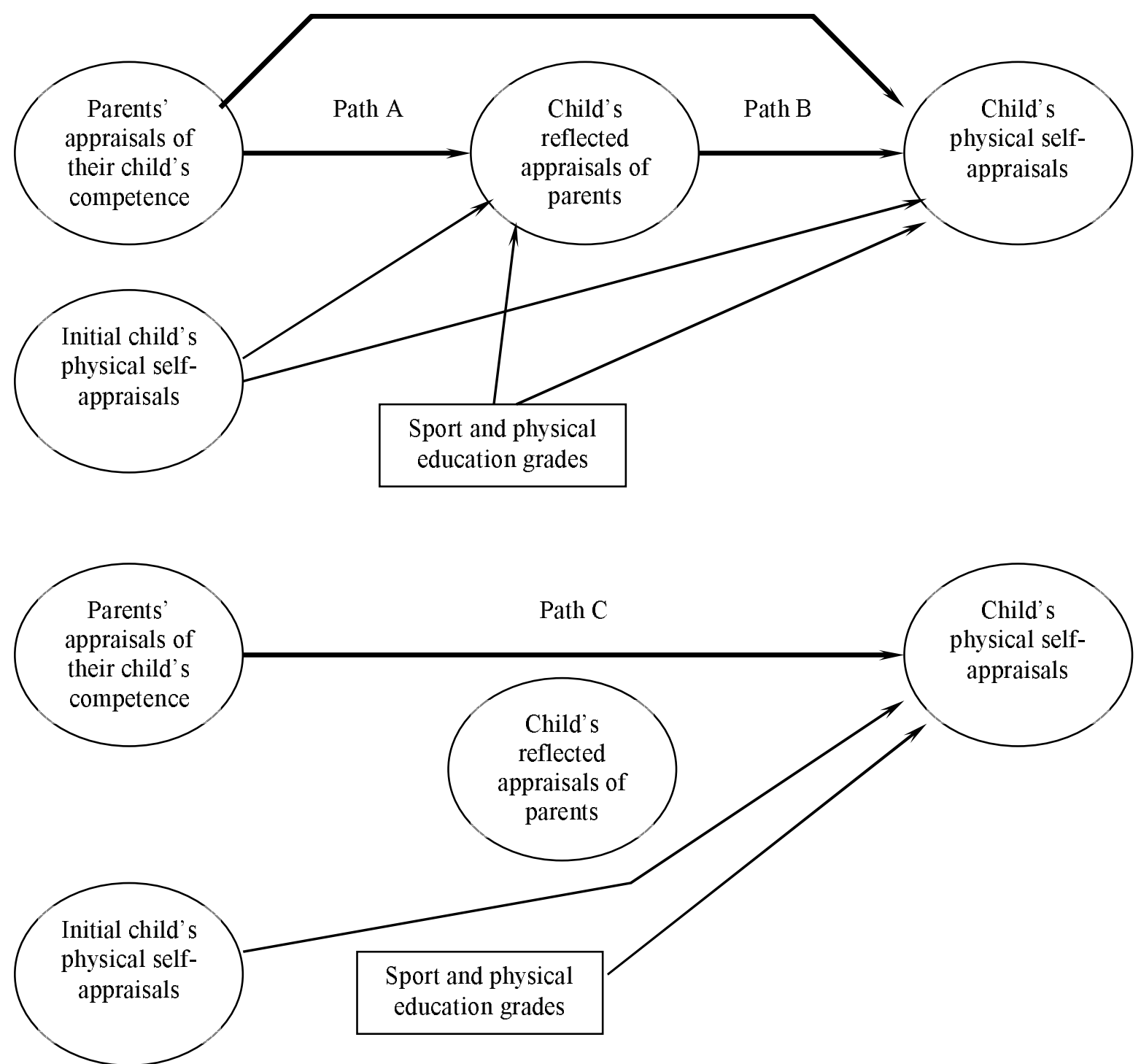



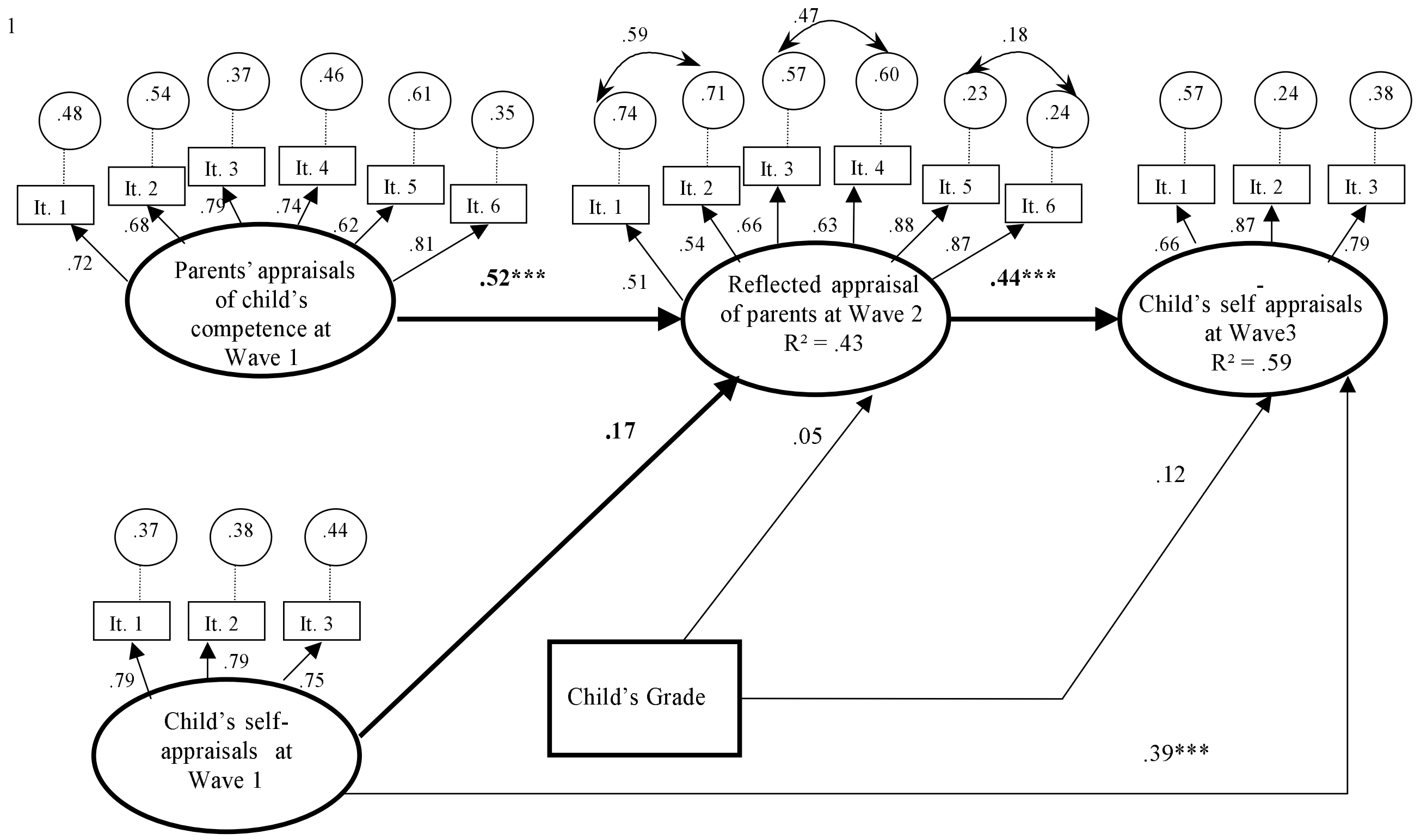

